\title{
Perceptions of Followers About Ethical Leadership and Attendant Effects on Organizational Success
}

\author{
Adejobi S. Odeneye \\ Walden University \\ Stephanie Hoon \\ Walden University \\ Karla S. Phlypo \\ Walden University
}

\begin{abstract}
Attainment of goals without consideration for the needs of stakeholders remains the focus of leaders. Ethical leadership (EL) studies' focus on leaders' perspectives represented a research gap that necessitated this study. Followers are the least researched among stakeholders; thus, this study explored EL from their viewpoints. Stakeholder theory, social learning theory, eudaimonia, and utilitarianism were the conceptual frameworks that guided this study. Twenty participants drawn from followers in a public organization in New Jersey were questioned about their experiences and expectations of EL using open-ended interview questions. Participants with shared experiences were selected based on convenience, snowball, and criterion sampling strategies. With the use of the transcendental phenomenological design, the data collected were analyzed with the Stevick-Colaizzi-Keen method and the two-cycle analysis. Knowledge, exemplarity, and democratic decision making were themes of EL that are relevant to followers. Other themes found in this study, including communication, stakeholders' well-being, impartiality, honesty, relationship building, responsibility, and humility, concur with extant literature and suggest consistency in the phenomenon. The potential social change implications of this study are an innovative and cooperative work environment, organizational success, and enhanced corporate social responsibility. Organizations and societies may benefit from the inculcation and development of EL in the family, society, tertiary institutions, and organizations through training, mentoring, and the development of an ethical culture.
\end{abstract}

Keywords: leadership, ethical leadership, business ethics, stakeholders, organization

\section{Introduction}

Inquiries by the U.S. Senate about the Wall Street collapse of 2008 revealed that executives of corporations knowingly and unethically sold loans and investments that were of no value (Clarke \& Bassell, 2013). Between 2008 and 2010, the U.S. government was compelled to insert more than $\$ 700$ billion into the economy to bail out ailing corporations that were considered too big to fail (Grove \& Cook, 2013). The impact of this Wall Street situation supported the importance of studying business ethics and ethical leadership (EL; Zhu, Trevino, \& Zheng, 2016). Addressing the interests and well-being of stakeholders in EL may alleviate the kind of problems precipitated by Wall Street.

This research was a microcosm of a doctoral project completed towards the award of a Ph.D. degree by Adejobi S. Odeneye. 
The problem identified in this study is that, despite the focus of leaders on goal attainment without due consideration of the impact on relevant stakeholders, current understanding of the phenomenon of EL is adversely swayed by leaders. This problem noted by Heres and Lasthuizen (2012) is that the characteristics of EL are predominantly explored from the perspectives of leaders as research participants. This study may help broaden knowledge of the phenomenon of EL, providing an understanding of the attributes of EL from the perspectives of followers.

\section{Background}

The need for EL in management came to the forefront with the collapse of major corporations like Enron and the financial breakdown in Wall Street that negatively affected the world economy in 2008. Interests in EL were further emphasized in recent times by the unethical corporate practices of Volkswagen in building mechanisms into their products to hide emissions. These unethical behaviors were partly blamed on the gross unethical practices of organizational leaders (Verschoor, 2015). Lately, the teaching of business ethics is being given a central place in the curriculum of business schools (Donaldson, 2015). Similarly, the study of EL continues to gain preeminence among business scholars (Wu, Kwan, Yim, Chiu, \& He, 2015).

The term ethical leadership is attributable to Enderle (1987) in attempting to understand the effect of leaders' decisions on others in the pursuit of organizational goals. Freeman and Stewart (2006) asserted that EL can be found in the solid character of the leader in the quest for values that are right. Understanding the characteristics of the ethical leader from followers' perspective is pertinent. Binns (2008) stated that the virtues of EL can be learned through formal training. Some scholars believed that the source of EL is rooted in faith and spirituality (King, 2008). Such assertions, though debatable, support the concept that EL can be learned, as it is not innate.

Extant literature on the phenomenon of EL is replete with diverse definitions of the term. For instance, Brown, Trevino, and Harrison, (2005) defined EL as the ability of leaders to act appropriately according to accepted norms and promote such conduct through their interactions with others, especially followers. Ciulla (1995) normatively defined EL as the ability of leaders to be concerned about the dignity and rights of others. Eisenbeiß and Brodbeck (2014) argued that the definition of EL as given by Brown et al. (2005) is based on a United States understanding of the concept, anchoring it on acceptable norms of behavior. Eisenbeiß and Brodbeck claimed that there is need for a definition that will recognize the possible influence of culture.

Different traits or characteristics of EL were identified and combined in varying proportions by different scholars. These features include humility (Patelli \& Pedrini, 2015), interest in stakeholders' well-being, honesty, interpersonal relationship building, and responsibility. Others include fairness (Kalshoven, den Hartog, \& De Hoogh, 2011), transparency, empowerment, and collectivism. Only four are highlighted in this article.

\section{Method}

The purpose of this transcendental phenomenological study was to explore the characteristics of EL as a lived experience from the viewpoints of followers in a public organization in New Jersey. The population for this study is followers in a public organization in New Jersey. A population has defined elements that fit prescribed criteria suitable for inclusion in a study (Chein, as cited in Frankfort-Nachmias \& Nachmias, 2008). This study's population excluded managers, supervisors, and all other employees who were not customer facing. A sample is a manageable number in proportion to the population and represents the population in a probabilistic or nonprobabilistic 
manner. Sample participants were selected based on the inclusion criteria of shared experiences and homogeneity as reflected in the same designation, minimum of a 4-year college degree, minimum of 5 years' experience with the organization, and being customer-facing or frontline employees. Convenience, snowball, and criterion sampling strategies were used concurrently and progressively in the selection of the sample size of 20 participants for this study. These participants were asked indepth, open-ended interview questions based on the central research question about their lived experiences regarding their expectations, understanding, and interpretations of the characteristics of EL. Data were collected from each participant individually in single but separate interviews for about 1 hr over a period of 1 month. Follow-up questions and member checking were conducted through emails.

The transcribed data collected during the interviews were coded for themes and commonalities using both hand coding and Nvivo. Data analysis in this study followed the seven steps phenomenological analysis recommended by Moustakas (1994) in a modification of the Stevick-Colaizzi-Keen method. In addition, to enhance triangulation, the data were further analyzed using the two-cycle analysis advocated by Miles, Huberman, and Saldana (2014).

\section{Results}

Only themes supported by the synthesis of the textural-structural descriptions of at least 10 coresearchers or participants were identified as the final themes. Based on this benchmark, from the 537 important statements we analyzed, 10 themes emerged as characteristics of EL from the perspectives of followers in this study. These include (a) transparency/communication, (b) stakeholders' well-being, (c) impartiality/fairness, (d) exemplarity, (e) knowledge/competence, (f) democratic decision making, (g) honesty, (h) relationship building, (i) responsibility, and (j) humility/respect (Table 1).

Table 1. Final Themes With Supporting Participants

\begin{tabular}{lc}
\hline Themes & Total Supporting Participants $(N=20)$ \\
\hline Transparency/communication & 19 \\
Stakeholders' well-being & 18 \\
Impartiality/fairness & 18 \\
Exemplarity & 17 \\
Knowledge/competence & 16 \\
Democratic decision making & 14 \\
Honesty & 14 \\
Relationship building & 14 \\
Responsibility & 11 \\
Humility/respect & 10 \\
\hline
\end{tabular}

For the purpose of brevity in this medium, only the first four of these results will be discussed indepth.

\section{Transparency/Communication}

Open communication, or transparency, is the most important characteristics an ethical leader should possess. The importance of building an organizational culture that will promote transparency in an ethical environment builds on its effect on employees' involvement and commitment toward the attainment of organizational goals (Niculescu, 2015). Participant E particularly emphasized that 
communication is the most important attribute of an ethical leader that will promote cooperation and remove avoidable confusion.

Not only is communication important, the tone of the communication and the manner in which it is presented matter for effectiveness "because you can get people to do a lot of things, ... the message can be the same, but it's the way that you deliver it that determines how people respond to it" (Participant G).

\section{Stakeholders' Well-Being}

The ethical leader is expected to be genuinely concerned about the well-being of stakeholders, especially subordinates. Ethical leaders' concern about stakeholders' well-being has been found to affect the performance of employees (Bouckenooghe, Zafar, \& Raja, 2015). Participant D asserted that priority should be given to the needs and well-being of followers to engender efficiency and success.

Participants in this study held that the attention paid by the ethical leader to the well-being of stakeholders has implication because "you know you have someone that has your back. So, that is going to make you work harder" (Participant S). Catering to stakeholders' well-being need not be lopsided, as it is possible for the ethical leader to "understand and think about what's good for the company and what's good for the people that work for you" (Participant $\mathrm{O}$ ).

\section{Impartiality/Fairness}

The characteristic of impartiality or fairness in EL was considered as important as stakeholders' well-being. This theme coincides with current findings in management in which the imperative for fairness in organizations and EL cannot be overemphasized. In the view of Participant V, though leaders may have different flairs, fairness, equality, and lack of favoritism are indispensable in EL.

The issue of partiality in promotion seemed to be of concern to many participants, and they would rather see the ethical leader display fairness in this regard. Participant $J$ lamented about "persons in positions as supervisors for example without knowledge of what they do, without any type of real educational background ... but they had the position, because it's not what you know, it's who you know." Participant F expressed a similar view that "certain managers were just given [positions] because they are politically connected ...." Participant E cautioned that one should not expect the ethical leader to be superhuman or perfect. In disagreement with the trend of partiality in promotion expressed, Participants $\mathrm{W}$ and $\mathrm{Q}$, who had put in over 16 years of service and are in the 61-69 and 70+ age brackets, respectively, expressed optimism based on the progress they had witnessed about fairness in promotion generally.

\section{Exemplarity}

The ethical leader is expected to be exemplary, leading by example. This exemplarity theme is in deviation from current trends on the phenomenon of EL. Participants in this study considered leading by example to be particularly important. Participant A pointed out that the behavior of the ethical leader cascades to the followers, thereby impacting the general ethical orientation of the organization.

Leaders should be conscious of their position as role models as subordinates may tend to emulate them with a considerable effect on the organization. An impressive majority of participants shared the view that the ethical leader should be a moral exemplar, worthy of emulation. This theme on the 
exemplarity role of the ethical leader is supported by Zhu et al. (2016) in confirming its influence in shaping the moral dispositions of followers. Participant U noted that "performance trickles down, it comes from the top down."

\section{Discussion}

Aside from the themes of exemplarity, knowledge/competence, and democratic decision making as distinct characteristics identified by participants in this study, other themes mentioned are in agreement with prior studies reviewed. Some features of EL, like empowerment, accountability, and collective focus identified in the extant literature reviewed, did not make it to the level of final themes in this study. Seven of the 10 characteristics identified in previous studies reviewed are also applicable to this study, indicating considerable consistency in the phenomenon of EL. This uniformity is not surprising, given that ethics, as the substratum of EL, has a perennial connotation that transcends sociocultural or spatial-temporal reality (Filip, Saheba, Wick, \& Radfar, 2016). Ethics, as the moral code of conduct in human interpersonal relationships, remains constant (Filip et al., 2016) despite changes discernible in society over time and in different cultures. On the other hand, the coalescence of the seven characteristics identified in this study with those of earlier research may be indicative that, in contrast to the opinion of Heres and Lasthuizen (2012), not much difference exists between the views of leaders queried in prior studies and followers queried in this study.

The characteristics of empowerment, collective focus, and accountability are not part of the final themes in this study. These represent a marked point of divergence in the current study from previous studies. This difference in finding validates the position of Heres and Lasthuizen (2012) that leaders queried in prior research may embellish the phenomenon of EL to make themselves look good. A similar argument may be that leaders employed in previous studies may genuinely, but erroneously, assume that certain characteristics should be important to most people in the organization. It is further possible that leaders naturally conceived these characteristics from the perspectives that are important to them, without realizing that some of the features may not be necessarily relevant to other stakeholders in the organization. The results from this study may enrich available knowledge on the phenomenon of EL through the presentation of a different, but unique, perspective of followers.

This study extends knowledge about the phenomenon of EL by identifying three new characteristics of EL: exemplary, democratic decision making, and knowledge/competence. Through identification of these characteristics of EL as final themes in this study, participants may help direct attention to these aspects as critical perspectives to followers, as distinct from what leaders find significant. Some of these characteristics may not be entirely new to EL discourse, as they may be subsumed under other categories. For instance, with regards to democratic decision making, Kalshoven et al. (2011) noted that EL entails allowing contributions to decision making from subordinates, thereby enhancing the quality and the acceptability of such decisions. Distinguishing democratic decision making, knowledge/competence, and exemplarity as final themes in this study may help to attract needed attention to them.

This finding considerably bridged the gap in literature identified by Heres and Lasthuizen (2012) that a need exists to explore the phenomenon of EL from the viewpoints of followers for a more robust comprehension of the phenomenon. Organizational leaders may now be able to appreciate, understand, and exhibit these characteristics that are peculiarly relevant to followers. The importance of such understanding will be made more pertinent when one realizes that followers constitute the majority of the workforce in any organization. Leaders need the support, 
contributions, and commitment of followers to be able to achieve organizational goals and ensure the organization remains competitive (García-Buades, Martínez-Tur, Ortiz-Bonnín, \& Peiró, 2016). Such support, commitment, and contributions will remain elusive if leaders fail to meet the expectations of followers. Meeting the expectations of followers will be enhanced considerably if leaders exhibit the characteristics of exemplarity, democratic decision making, and knowledge/competence that are found in this study to be particularly important to employees.

The characteristics identified in this study need to be properly contextualized for relevancy during application. Different organizational contexts may warrant the need for the modification of some of these characteristics. For instance, although open communication or transparency and honesty may be characteristics an ethical leader should possess, the need for confidentiality must be considered and respected. Also democratic decision making in a military setting and during the time of unplanned change or crisis may be subjugated to the reality of urgency that requires an immediate and peremptory decision.

\section{Implications for Social Change}

At the individual level of positive social change, this study has the potential to increase job satisfaction among employees. Because ethical leaders encourage employees to voice their opinions unencumbered, employees may generate innovative ideas (Szczepanska-Woszczyna, 2014). Individual relationships between followers and leaders may improve due to EL. The trust immanent in the perception of a leader as ethical is becoming increasingly important in a global business environment where leaders must address and need the cooperation of followers in global virtual teams.

This study may have implications for positive social change in the organizational dimension. The success of the organization regarding goal attainment, profitability, the harnessing of resources, innovation, and competitiveness require the ethical capability of leaders. Subordinates may be better attuned to accept and support the implementation of change when the leader is perceived to be ethical (Babalola, Stouten, \& Euwema, 2016). EL may enhance the possibility of overall stakeholders' satisfaction.

At the societal level of positive social change, ethical leaders who are not egotistic but focused on the well-being of others may increase effective and relevant corporate social responsibility initiatives in the society (Agudo-Valiente, Garces-Ayerbe, \& Salvador-Figueras, 2015). EL may help stem the endemic corruption in society that nearly led to the economic recession recorded in the United States in 2008 with its ripple effects that jolted the world economy-leading to a more stable economy (Verschoor, 2015).

This study has implications for practice that may be beneficial at the organizational, academic, and societal levels. Corporate leaders need to be constantly conscious of the effects of their actions and behaviors on subordinates as this may impact the general ethical climate in the organization. The relationship building and communication characteristics of the ethical leader may improve through the establishment of a formal feedback mechanism in the organization. Feedback should be frequent and include peers, managers, customers, and the organization (Kurra \& Barnett, 2016). It is not sufficient for leaders to simply gather feedbacks perfunctorily; it is necessary and important to implement those that may be beneficial towards the realization of organizational goals.

The expectation of absolute impartiality, devoid of favoritism of any kind, especially in promotion, appointments, and hiring, may be farfetched and unrealistic. Cadsby, Du, and Song (2016) found that individuals often show favoritism to people who are close to them, even when such an act does 
not directly benefit them. For the ethical leader to remain mostly impartial while acknowledging social realities, we propose a model of an 80:20\% ratio rule to fairness. Ethical leaders should ensure that minimally $80 \%$ of appointments, promotions, and hiring are scrupulously based on merit, whereas maximally only $20 \%$ is reserved to accommodate any extenuating social reality that may border on any form of favoritism. Adopting this rule may increase competency in the organization while boosting the confidence of employees that they have a significant opportunity for advancement through skills, experience, qualification, and commitment.

One mode of acquisition of EL characteristics that participants in this study noted is through developmental growth. Brown and Trevino (2014) noted that informal training in EL starts at the family level and pinnacles in the work environment. It may be beneficial for organizations to consider the establishment of buddy-mentoring programs. The buddy-mentoring program should involve the identification of subordinates who are interested in or have the potential to become future leaders and matching them with current ethical leaders who can advise them as they progress.

The implication for practice at the academic level may revolve around EL training in tertiary institutions. Another mode of acquisition of EL characteristics that participants pointed out in this study is formal training. Colleges need to understand the imperative to teach the fundamentals and complexities of EL in schools. Such ethical teachings should not be limited to business or management schools. EL training should be made compulsory for all university or college students because graduates from the liberal arts or pure and applied sciences have risen to become heads of large global corporations without having had any formal business or management training.

This formal training in EL should not be limited to the school environment but can expand to include periodic ethical training in the organization. Such intermittent moral training will serve as a constant reminder of its organizational relevance while underscoring its applicability to leaders and followers alike. Training needs to be reflexive, allowing for the deft integration of practice with theory (Hibbert \& Cunliffe, 2015), leading to a reduction in unnecessary abstraction and disengagement.

Because culture impacts the perception of EL, society has a role to play in shaping a culture that is ethically centered. What is acceptable or tolerated as ethical in one culture may be vehemently opposed in another culture (Fok, Payne, \& Corey, 2016). Just as it is possible to build an organizational culture based on ethical values (Wu et al., 2015), society as a whole can and should consciously, over time and with determination, shape the culture to reflect moral orientation. When society frowns at unethical behaviors, eschewing such at individual and family levels will be easy, given the assertion of Brown and Trevino (2014) that parents are the most influential in role modeling at the childhood level.

\section{Recommendations}

Future researchers should focus on using followers as study participants in the understanding of the characteristics of EL for possible replication. Following the suggestion of Sharif and Scandura (2014), a comparative analysis of the viewpoints of different stakeholders on the phenomenon of EL may be conducted. Also, private organizations may be used in future research to increase the robustness of the knowledge on the phenomenon of EL.

Findings from this exploratory qualitative study may further be assessed quantitatively in future studies to enhance the possibility of generalization. Using the quantitative method to evaluate the results of a qualitative study may reduce the limitation inherent in one approach (Venkatesh, 
Brown, \& Sullivan, 2016). Differences in cultural orientations influence the manner by which individuals understand and address ethical issues (Fok et al., 2016). A need may exist for further research that will help underscore the importance of the impact of culture on the phenomenon of EL.

\section{Conclusion}

This study contributes to current research on the phenomenon of EL by presenting the views of followers about the characteristics of EL, in contrast to past studies in which leaders were used as research participants. Characteristics like exemplarity, knowledge/competence, and democratic decision making, which were muffled in the extant literature reviewed, were relevant to followers as participants in this study. Similarities between some of the characteristics of EL identified by leaders as participants in the existing literature and those identified by followers in this study underscore the uniformity inherent in the phenomenon. These characteristics include transparency/communication, stakeholders' well-being, impartiality/fairness, honesty, relationship building, responsibility, and humility/respect.

Understanding the expectations of followers from an ethical leader, in alignment with stakeholder theory, may raise the level of commitments of employees to the attainment of organizational goals, increase innovative ideas, and enhance customer satisfaction. Corporate social responsibility and economic growth may be some of the benefits of EL to society, as ingrained in utilitarianism and eudaimonia. Built on social learning theory (Bandura, 1977), laying a sound foundation for the development of EL should start from the family as a unit of society. Tertiary institutions of learning should endeavor to instill the characteristics of EL in all students by including it in their core curriculum. Organizations can build on the efforts of society and postsecondary institutions through selective hiring, mentoring program, and recurrent ethical training.

\section{References}

Agudo-Valiente, J. M., Garces-Ayerbe, C., \& Salvador-Figueras, M. (2015). Corporate social performance and stakeholder dialogue management. Corporate Social Responsibility and Environmental Management, 22, 13-31. doi:10.1002/csr.1324

Babalola, M., Stouten, J., \& Euwema, M. (2016). Frequent change and turnover intention: The moderating role of ethical leadership. Journal of Business Ethics, 134, 311-322. doi:10.1007/s10551-014-2433-z

Bandura, A. (1977). Social learning theory. Upper Saddle River, NJ: Prentice Hall.

Binns, J. G. (2008). The ethics of relational leading: Gender matters. Gender, Work \& Organization, 15, 600-620. doi:10.1111/j.1468-0432.2008.00418.x

Bouckenooghe, D., Zafar, A., \& Raja, U. (2015). How ethical leadership shapes employees' job performance: The mediating roles of goal congruence and psychological capital. Journal of Business Ethics, 129, 251-264. doi:10.1007/s10551-014-2162-3

Brown, M. E., \& Trevino, L. (2014). Do role models matter? An investigation of role modeling as an antecedent of perceived ethical leadership. Journal of Business Ethics, 122, 587-598. doi:10.1007/s10551-013-1769-0

Brown, M. E., Trevino, L. K., \& Harrison, D. A. (2005). Ethical leadership: A social learning perspective for construct development and testing. Organizational Behavior and Human Decision Processes, 97, 117-134. doi:10.1016/j.obhdp.2005.03.002 
Cadsby, C. B., Du, N., \& Song, F. (2016). In-group favoritism and moral decision-making. Journal of Economic Behavior \& Organization, 128, 59-71. doi:10.1016/j.jebo.2016.05.008

Ciulla, J. B. (1995). Leadership ethics: Mapping the territory. Business Ethics Quarterly, 5, 5-24.

Clarke, C., \& Bassell, M. (2013). The financial debacle necessitates a systematic approach to achieving ethical behavior in the corporate workplace. Journal of Business Systems, Governance \& Ethics, 8, 22-33. doi:10.15209/jbsge.v8i1.327

Donaldson, T. (2015). Where the facts end: Richard De George and the rise of business ethics. i, 783787. doi:10.1007/s10551-014-2187-7

Eisenbeiß, S. A., \& Brodbeck, F. (2014). Ethical and unethical Leadership: A cross-cultural and cross-sectoral analysis. Journal of Business Ethics, 122, 343-359. doi:10.1007/s10551-013$1740-0$

Enderle, G. (1987). Some perspectives of managerial ethical leadership. Journal of Business Ethics, 6, 657-663. doi:10.1007/BF00705782

Filip, I., Saheba, N., Wick, B., \& Radfar, A. (2016). Morality and ethical theories in the context of human behavior. Ethics \& Medicine: An International Journal of Bioethics, 32, 83-87.

Fok, L., Payne, D., \& Corey, C. (2016). Cultural values, utilitarian orientation, and ethical decision making: A comparison of U.S. and Puerto Rican professionals. Journal of Business Ethics, 134, 263-279. doi:10.1007/s10551-014-2426-y

Frankfort-Nachmias, C., \& Nachmias, D. (2008). Research methods in the social sciences (7th ed.). New York, NY: Worth.

Freeman, E., \& Stewart, L. (2006). Developing ethical leadership. Business Roundtable Institute for Corporate Ethics. Retrieved from http://www.corporate-ethics.org/pdf/ethical_leadership.pdf

García-Buades, E., Martínez-Tur, V., Ortiz-Bonnín, S., \& Peiró, J. M. (2016). Engaged teams deliver better service performance in innovation climates. European Journal of Work \& Organizational Psychology, 25, 597-612. doi:10.1080/1359432X.2016.1171752

Grove, H., \& Cook, T. (2013). Lehman Brothers and Bear Stearns: Any financial and corporate governance differences? Amity Global Business Review, 8, 112-130.

Heres, L., \& Lasthuizen, K. (2012). What's the difference? Ethical leadership in public, hybrid and private sector organizations. Journal of Change Management, 12, 441-466. doi:10.1080/14697017.2012.728768

Hibbert, P., \& Cunliffe, A. (2015). Responsible management: Engaging moral reflexive practice through threshold concepts. Journal of Business Ethics, 127, 177-188. doi:10.1007/s10551013-1993-7

Hume, D. (1889). The natural history of religion. London, United Kingdom: A. and H. Bradlaugh Bonner.

Kalshoven, K., den Hartog, D., \& De Hoogh, A. (2011). Ethical leader behavior and big five factors of personality. Journal of Business Ethics, 100, 349-366. doi:10.1007/s10551-010-0685-9

Kant, I. (2012). The critique of practical reason. New York, NY: Start. (Original work published 1788)

King, M. (2008). Robert Audi, Practical reasoning and ethical decision [Book review]. Ethics, 118, 717-721. doi:10.1086/590540

Kurra, G., \& Barnett, J. (2016). The future of feedback: Frequent, candid, and entirely more effective. Workforce Solutions Review, 7, 8-12. 
Miles, M. B., Huberman, A. M., \& Saldana, J. (2014). Qualitative data analysis: A methods sourcebook (3rd ed.). Thousand Oaks, CA: Sage.

Moustakas, C. (1994). Phenomenological research methods. Thousand Oaks, CA: Sage.

Niculescu, D. (2015). Key features in knowledge-driven companies. Management Dynamics in the Knowledge Economy, 3, 45-60.

Patelli, L., \& Pedrini, M. (2015). Is tone at the top associated with financial reporting aggressiveness? Journal of Business Ethics, 126, 3-19. doi:10.1007/s10551-013-1994-6.

Sharif, M., \& Scandura, T. (2014). Do perceptions of ethical conduct matter during organizational change? Ethical leadership and employee involvement. Journal of Business Ethics, 124, 185196. doi:10.1007/s10551-013-1869-x

Szczepanska-Woszczyna, K. (2014). Innovation processes in the social space of the organization. Regional Formation and Development Studies, 14, 220-229. doi:10.15181/rfds.v14i3.878

Venkatesh, V., Brown, S. A., \& Sullivan, Y. W. (2016). Guidelines for conducting mixed-methods research: An extension and illustration. Journal of the Association for Information Systems, 17, 435-495.

Verschoor, C. C. (2015). Whistleblowers take big risks. Strategic Finance, 97, 17-18.

Wu, sL., Kwan, H., Yim, F., Chiu, R., \& He, X. (2015). CEO ethical leadership and corporate social responsibility: A moderated mediation model. Journal of Business Ethics, 130, 819-831. doi:10.1007/s10551-014-2108-9

Zhu, W., Trevino, L. K., \& Zheng, X. (2016). Ethical leaders and their followers: The transmission of moral identity and moral attentiveness. Business Ethics Quarterly, 26, 95-115. doi:10.1017/beq.201

The Journal of Social Change, sponsored by Walden University, welcomes manuscripts focusing on interdisciplinary research in social change that improves the human condition and moves people, groups, organizations, cultures, and society toward a more positive future.

Walden University Publishing: http://www.publishing.waldenu.edu 